\title{
A search for the presence of the enteroviral capsid protein VP1 in pancreases of patients with Type 1 (insulin-dependent) diabetes and pancreases and hearts of infants who died of coxsackieviral myocarditis
}

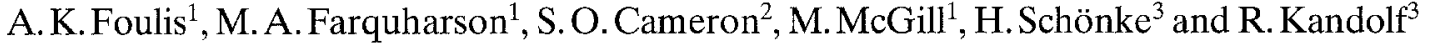 \\ Departments of 1 Pathology, and ${ }^{2}$ Medical Virology, Royal Infirmary, Glasgow, UK, and \\ ${ }^{3}$ Max-Planck-Institut für Biochemie, Martinsried, FRG
}

\begin{abstract}
Summary. Using an antiserum raised to a recombinant coxsackie virus B3 capsid protein, VP1, an immunocytochemical technique was developed which was capable of detecting the presence of all coxsackie $B$ viruses in formalin fixed paraffin embedded infected tissue culture cells. This technique was tested on autopsy heart and pancreas from 21 patients who were thought to have died of acute coxsackievirus B myocarditis. Cardiac myocytes were positive for the VP1 protein in 12 of 20 cases where the heart was available for study. Insulitis was present in the pancreas in seven of these cases and in all seven islet endocrine cells containing VP1 were found. VP1 was only rarely found in exocrine pancreas. In heart and pancreas, cells shown to contain VP1 usually showed signs of necrosis. Autopsy pancreases from $88 \mathrm{pa}-$
\end{abstract}

tients who had died at clinical presentation of Type 1 (insulin-dependent) diabetes mellitus showed no evidence of the presence of VP1. The continuing destruction of insulinsecreting $B$ cells seen at the time of death in the diabetic pancreas is unlikely to be due to a direct cytopathic effect of a coxsackie $B$ virus. However, this study does not exclude the possibility that a persistent infection of $B$ cells by a defective enterovirus may result in their destruction by an autoimmune mechanism.

Key words: Type 1 (insulin-dependent) diabetes mellitus, coxsackie B virus, pancreas, VP1 capsid protein, pancreatitis, myocarditis.
It is generally accepted that there is a major genetic component in the aetiology of Type 1 (insulin-dependent) diabetes mellitus in man. Thus far this has been primarily linked to class II major histocompatibility complex (MHC) genes [1, 2]. However, the relatively high prevalence of these susceptibility genes in the general community [1] and the fact that the concordance rate for the disease in monozygotic twins is only approximately $50 \%$ [3] has led to the conclusion that environmental factors must also play a part in the pathogenesis of the disease.

Viruses have long been suspected of playing a role in this process and in recent years coxsackie $B$ viruses in particular have been implicated. Up to $30 \%$ of newly diagnosed patients with Type 1 diabetes were shown to have IgM antibodies to coxsackie B viruses (types 1-5) compared to $6 \%$ of control subjects [4]. Secondly, a coxsackievirus B 4 was cultured from the pancreas of a ten-year-old boy admitted to hospital with recent onset Type 1 diabetes [5] and a coxsackievirus B 4 was demonstrated by immunofluorescence in islets of a five-year-old girl who died of the same disease [6]. Finally, coxsackie B viruses have been shown to cause endocrine cell necrosis in the human pancreas $[7,8]$.
A variety of immunological abnormalities are present in the islets of newly diagnosed Type 1 diabetic patients. These include abberant expression of class II MHC molecules by B cells $[9,10]$ hyperexpression of class I MHC by all the endocrine cells in insulin-containing islets [11] and the presence of alpha-interferon in B cells in islets which hyperexpress class I MHC [12]. It has been hypothesized that secretion of alpha-interferon by $B$ cells is an early event in the evolution of the diabetic process $[12,13]$. Among control pancreases of patients who had died of diseases other than Type 1 diabetes alpha-interferon was detected in B cells in four cases of neonatal viral pancreatitis, three of which were thought to be due to coxsackieviruses. This finding suggested that the B cells which express alpha-interferon in diabetic pancreases may harbour a non-cytopathic virus.

Recently, coxsackievirus B3 capsid proteins have been expressed in Escherichia coli from subgenomic fragments of infectious recombinant coxsackievirus B3 cDNA [14]. Fusion proteins containing firstly, the viral structural proteins VP4, VP2 and VP 3, and secondly, the VP1 structural protein, were isolated and these were then used to raise two polyclonal antisera in rabbits. These antisera were shown to cross react with capsid proteins of 
Table 1. Presence of capsid proteins VP 1 and VP $4 / 2 / 3$ in heart and pancreas in patients with presumed coxsackie B myocarditis

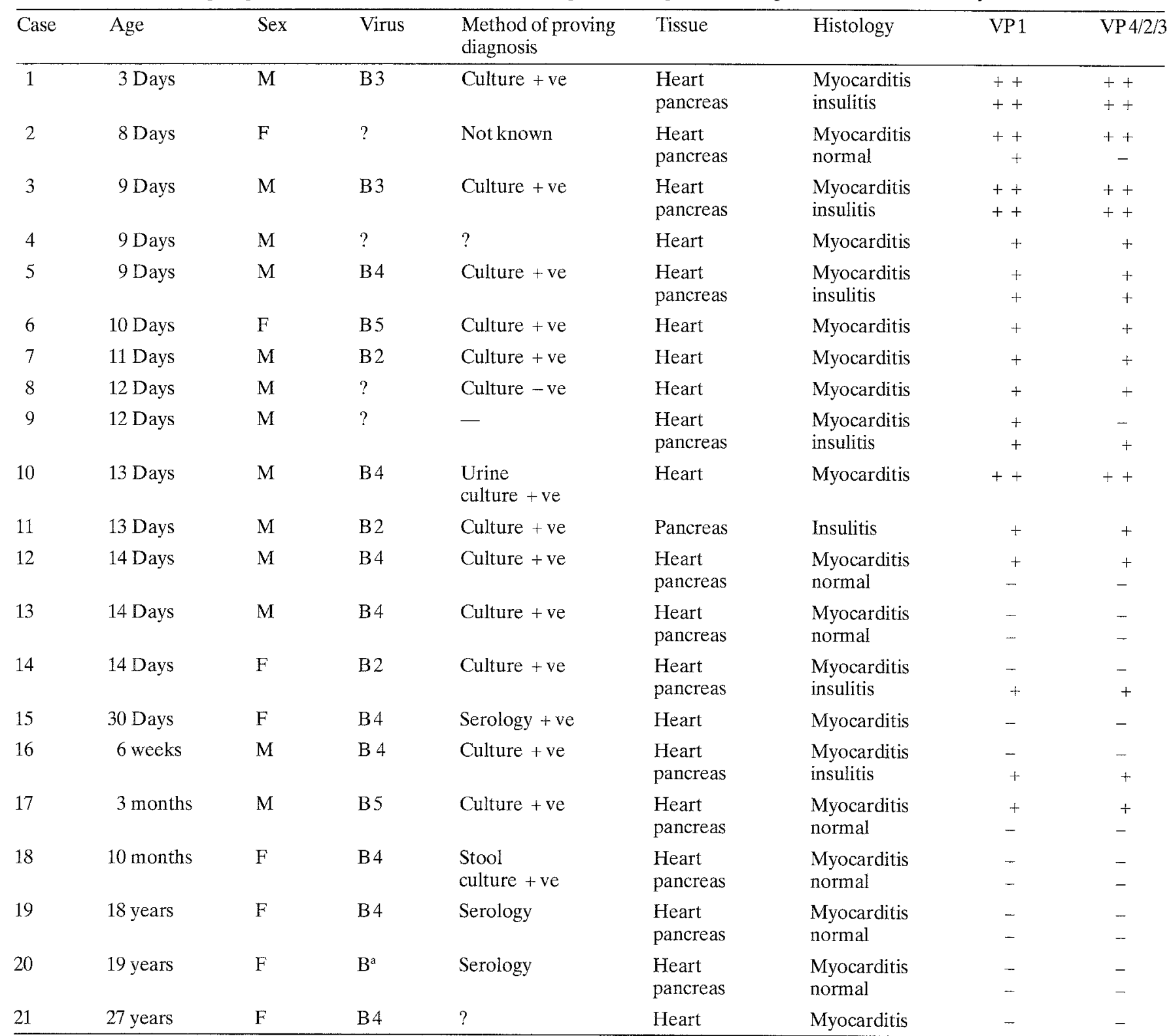

$+=$ focal islet endocrine staining or occasional positive myocytes; $++=$ many islets with endocrine cells staining or widespread myocardial positivity. Culture + ve refers to culture of tissue at autopsy. Pancreas was never cultured.

a cross reacting IgM antibody to B1, B2, B5 indicative of untyped recent Coxsackie B infection

a wide variety of enteroviruses, including all coxsackie B viruses.

We report here attempts to detect enteroviral capsid proteins using these reagents in autopsy pancreases of patients with Type 1 diabetes and autopsy tissues of patients thought to have died of coxsackie $\mathrm{B}$ virus infection.

\section{Subjects, materials and methods}

Formalin fixed, paraffin embedded blocks of pancreas were available from 149 autopsies on patients who had had Type 1 diabetes. Eighty-eight patients with an age range of $1-37$ years had died of recent-onset disease (less than 1 years's duration) and of these, 84 had residual $B$ cells in pancreatic tissue. Nineteen patients had had symptoms for less that one week and 27 for less than two weeks.
Fifty-nine patients (age range 3-37 years) had been diabetic for more than 1 year (range 1-19 years) and of these 19 had residual pancreatic Beta cells. Two cases in whom pancreatic B cells were present had disease of unknown duration. The male to female ratio among the diabetic patients was 59:90.

With the help of the computerised records of the Office of Population Censuses and Surveys a search was made of death certificates in England and Wales for children under the age of ten years who had died of coxsackie myocarditis. Where an autopsy had been performed blocks of heart and pancreas were sought from the appropriate pathologist. Additional cases were kindly provided by other pathologists who knew of this work (see Acknowledgements). Twenty-one cases were finally included (Table 1). Heart tissue was available for 20 cases and pancreas for 14 .

Control tissues were sought from the pathology files of the Royal Infirmary and Royal Hospital for Sick Children, Glasgow. These included blocks of normal autopsy pancreas from 11 neonates, normal autopsy pancreas from 21 children aged $1-12$ years, normal autopsy 


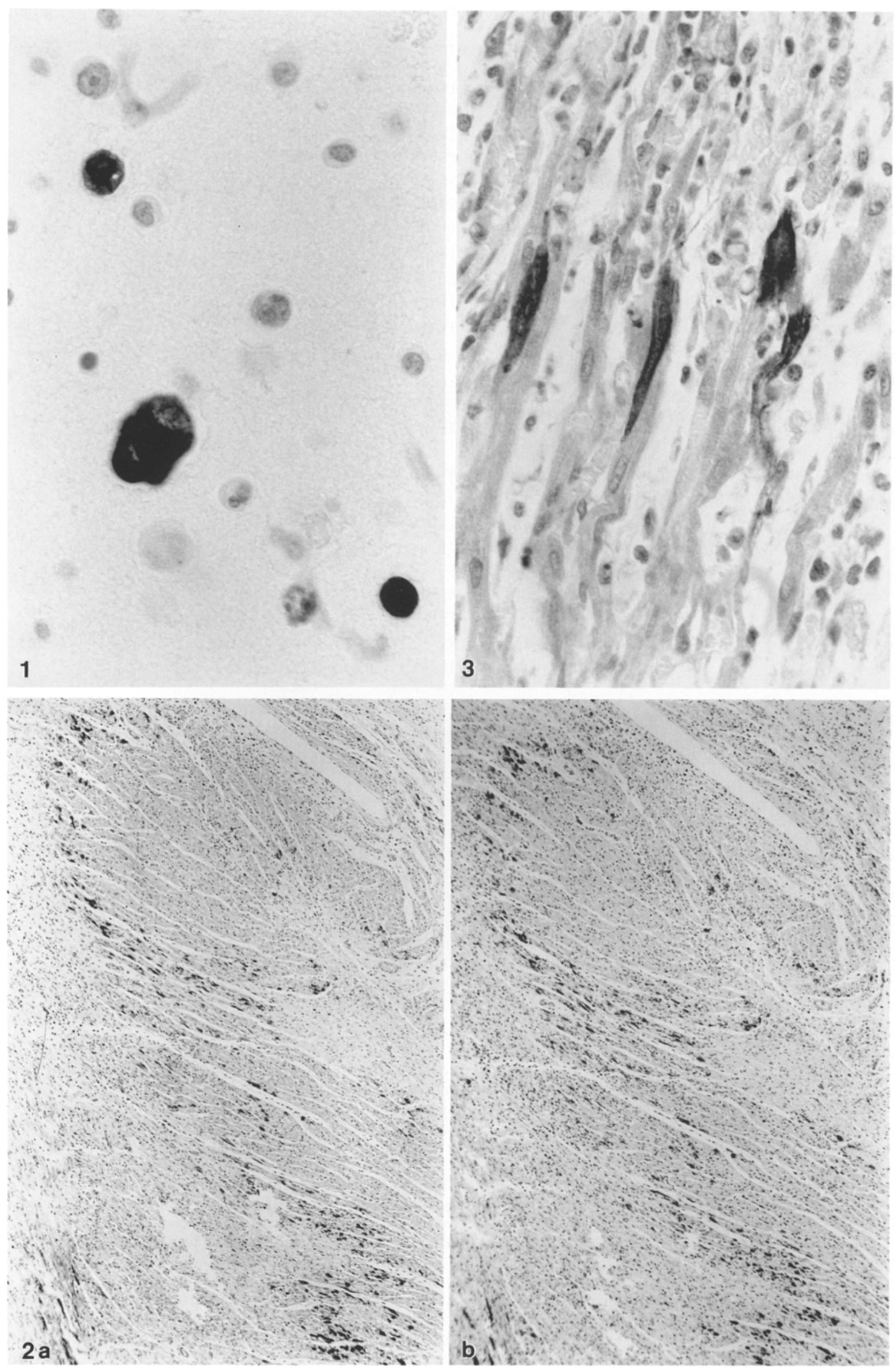


pancreas from 11 adults, pancreatic resections from 13 adult patients with chronic pancreatitis, autopsy pancreas from two adult patients with acute pancreatitis, normal autopsy myocardium from 11 neonates and autopsy myocardium from 10 adults, 5 of whom had evidence of recent infarction with associated inflammation.

To provide positive control material and study the range of identifiable viruses, coxsackie B viruses (types 1 to 6) coxsackievirus A 9, and echoviruses 22 and 11 , were cultured in Hep 2 tissue culture cells. When evidence of a cytopathic effect was seen the cells were extracted from culture, centrifuged into a pellet, fixed in formalin and processed in the standard manner used for formalin fixed tissues to paraffin blocks. Uninfected Hep 2 cells were similarly processed to provide a negative control.

Immunohistochemical staining of cells and tissues was performed as follows. Sections were dewaxed, rehydrated and endogenous peroxide was blocked with methanol: $\mathrm{HCl} \mathrm{H}_{2} \mathrm{O}_{2}$. After washing, goat serum, diluted 1 in 5 was added. The primary rabbit antiserum was then applied to the sections overnight at $4^{\circ} \mathrm{C}$. The antiserum to VP 1 was used at a dilution of 1 in 400 and that to VP $4 / 2 / 3$ at 1 in 800 . After washing, goat serum was again added to the sections. Next, biotin labelled goat anti-rabbit immunoglobulins (Vector Laboratories, Peterborough, UK) was applied at a dilution of 1 in 200 for $30 \mathrm{~min}$ at room temperature. After washing, avidin-biotin complexed to peroxidase (Vectastain ABC peroxidase kit, Vector Laboratories) was added for $60 \mathrm{~min}$ at room temperature. After washing, diaminobenzidine was added for $10 \mathrm{~min}$, producing a brown reaction product.

Adjacent sections of all pancreases were stained for insulin and glucagon using indirect immunoperoxidase techniques which have been described previously [10].

In order to assess which endocrine cells in islets were positive for viral proteins, a double staining technique was used in which sections were stained with the above technique for VP1 protein and then subsequently stained for insulin or glucagon using immunofluorescence. The method used the avidin biotin complex immunohistochemical technique described above for staining VP 1 up to the development of the diaminobenzidine substrate. After this had been done the sections were thoroughly washed. Double staining for insulin was done by a subsequent $4 \mathrm{~h}$ incubation of guinea pig anti-insulin antiserum (Dako, High Wycombe, UK) followed by a 30 min incubation of rabbit anti-guinea pig immunoglobulins (Dako). This was followed by a $30 \mathrm{~min}$ incubation of rhodamine-conjugated swine anti-rabbit immunoglobulins (Dako). Double-staining for glucagon was done by following the VP1 staining with a $4 \mathrm{~h}$ incubation with rabbit antiglucagon antiserum (Dako) and finally a $30 \mathrm{~min}$ incubation with rhodamine-conjugated swine anti-rabbit immunoglobulins. Double-stained sections were viewed and photographed using a Leitz Orthomat microscope.

\section{Results}

When applied to normal human tissue sections the immunoperoxidase methods for detection of VP1 and VP 4/2/3, which used an avidin biotin complex system, both gave a minor problem in that erythrocytes stained positively in some cases. Very rarely macrophages in areas of haemorrhage also stained, possibly the result of their phagocytos-

Fig. 1. Hep2 tissue culture cells infected with coxsackievirus B4. There is strong cytoplasmic staining of some cells using the immunohistochemical technique for the detection of VP 1. ( $\times 570)$

Fig. 2 a, b. Coxsackievirus B 4 myocarditis (case 10). Heart serial sections have been immunostained for VP 1 in (a) and VP 4/2/3 in (b). The staining patterns are virtually identical. $(\times 70)$

Fig. 3. Same case as shown in Figure 2. Myocytes positive for the VP1 protein are seen adjacent to inflammatory cells. $(\times 570)$ ing the cross reacting substance found in erythrocytes. In cases where erythrocytes were positive with these immunoperoxidase techniques they were also positive when normal rabbit serum was substituted for the primary antiserum, but were negative when rabbit serum was omitted. It will be appreciated that this cross reaction in no way interfered with assessing the positivity of heart myocytes or pancreatic parenchymal cells.

A more serious problem was encountered with the antiserum to VP $4 / 2 / 3$ on pancreatic sections. In approximately half of the normal pancreases very weak staining was observed on a minority of islet endocrine cells. While this could readily be distinguished from the strong positive staining of islet cells seen in some of the coxsackie viral cases it was thought to be an unsuitable reagent for screening the diabetic pancreases because of the risk of producing false positive results. These were therefore only screened for the presence of VP1. While it is likely that the immunohistochemical technique using the antiserum to VP 4/2/3 could be modified to overcome this problem we confined its use to confirming positive results obtained using the VP1 antiserum in the cases of known coxsackievirus infection.

\section{Infected tissue culture cells}

Tissue culture cells infected with coxsackie B viruses (types 1-6) were stained positively by antisera to both VP1 and VP4/2/3 (Fig. 1). Uninfected Hep2 cells were negative. In addition the antiserum to VP1 was tested against cells infected by coxsackievirus $\mathrm{A} 9$ and echoviruses 22 and 11 and was shown to stain such cells positively.

\section{Patients with coxsackievirus B infection}

Eighteen of the patients with presumed coxsackie B myocarditis were infants and three were young adults (Table 1). In eleven cases culture of organs at autopsy was positive for a coxsackie B virus. In two cases the diagnosis was made during life by culture of urine and stool respectively and three cases were diagnosed by serology only. Records were incomplete in cases 2, 4 and 21 and in case 9 a presumptive diagnosis was made purely on histology. Attempted culture at autopsy was made in case 8 but this proved negative. Of the typed infections three were coxsackievirus $\mathrm{B} 2$, two $\mathrm{B} 3$, nine $\mathrm{B} 4$ and two $\mathrm{B} 5$.

Myocardium was available for study in 20 cases and all showed varying degrees of inflammation. Myocyte necrosis was present in most infantile cases but was not convincingly seen in the three adult cases. Myocytes positive for both VP 1 and VP4/2/3 were present in 11 cases. In case 9 VP 1 stained a very occasional myocyte while VP 4/2/3 was negative. In general the staining pattern with both antisera to the capsid proteins was identical (Fig. 2). Coxsackieviruses B2 to B5 were all represented in the positive cases and the interval between death and autopsy did not appear critical, being up to $60 \mathrm{~h}$ in positive examples (case 10) (Fig.3). Myocytes which were positive 


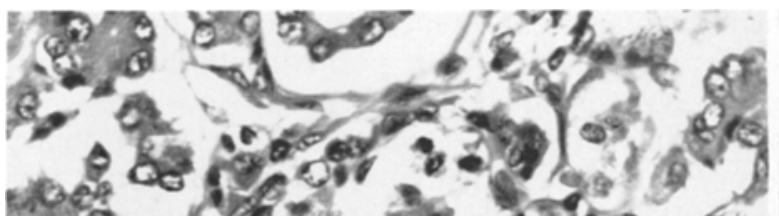

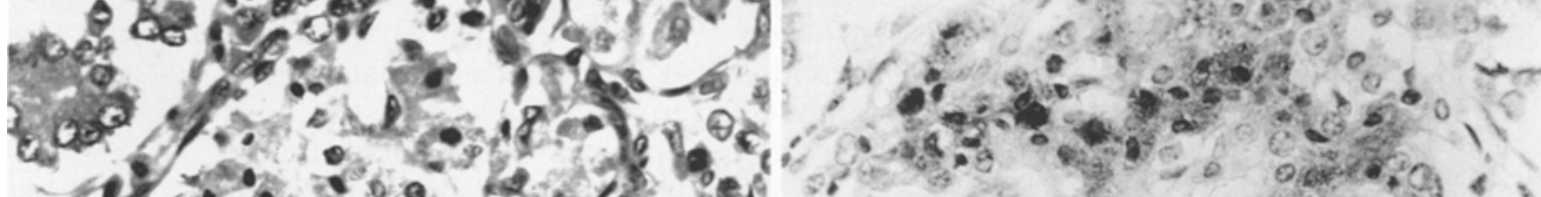

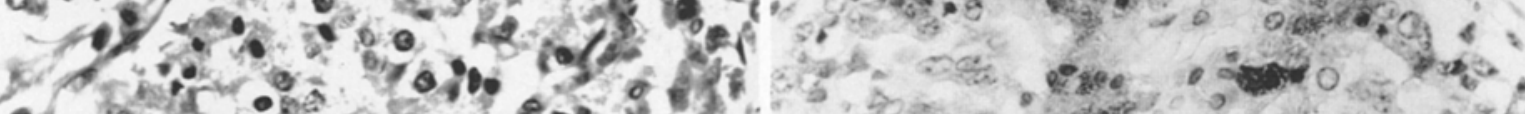

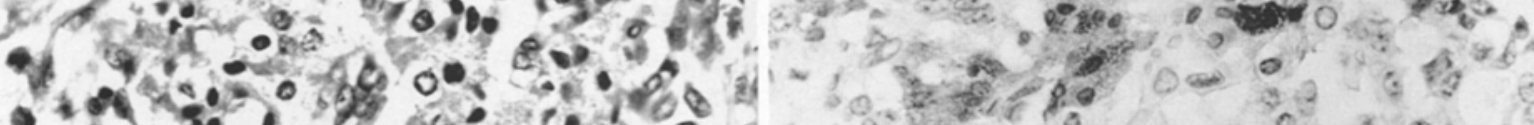

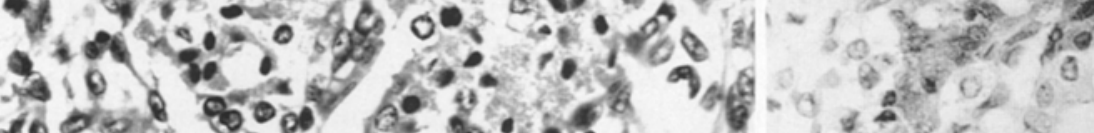

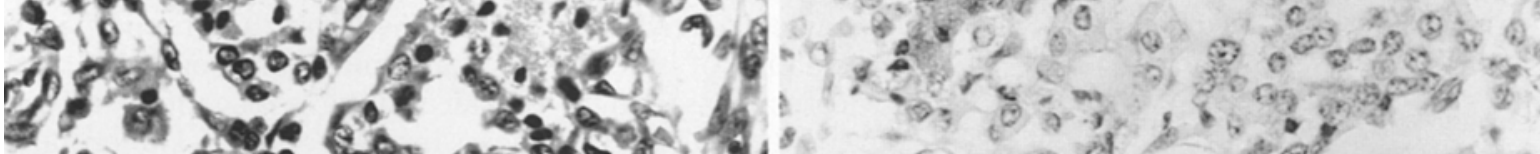

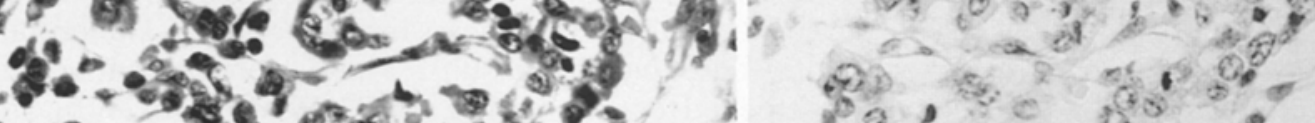

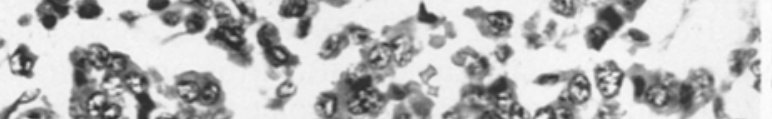

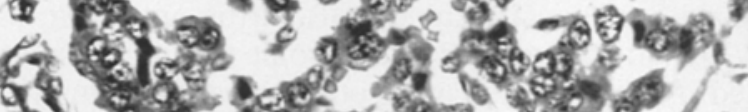

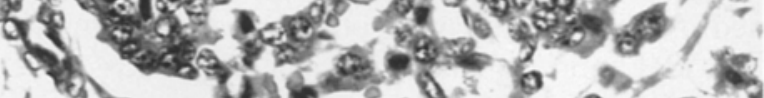
$\therefore$.

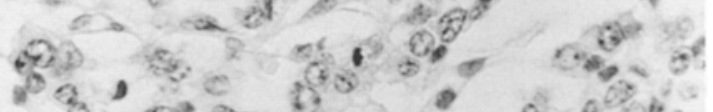
Q 00 .

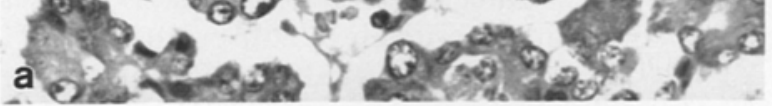

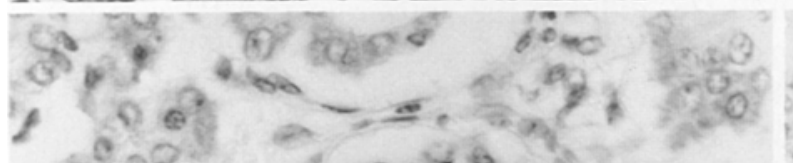
b 20

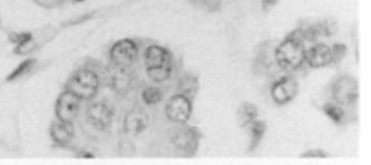

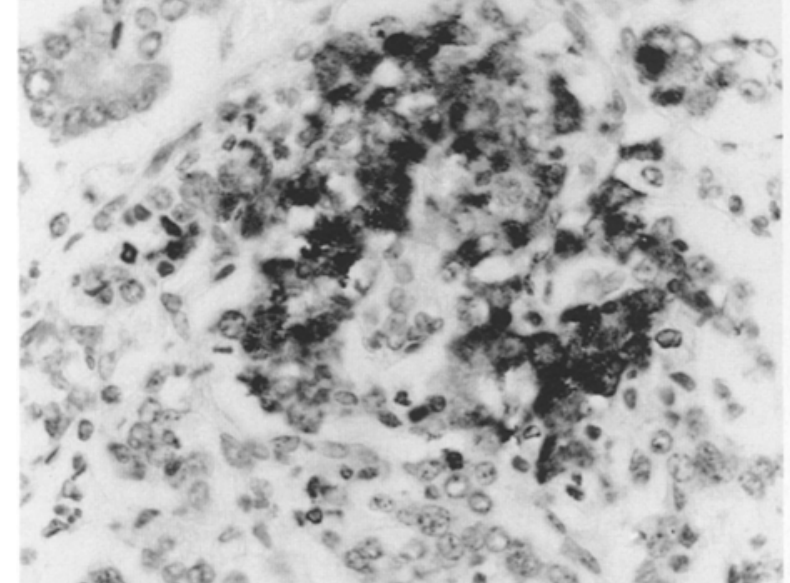

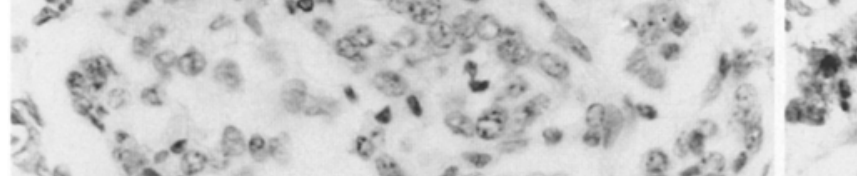

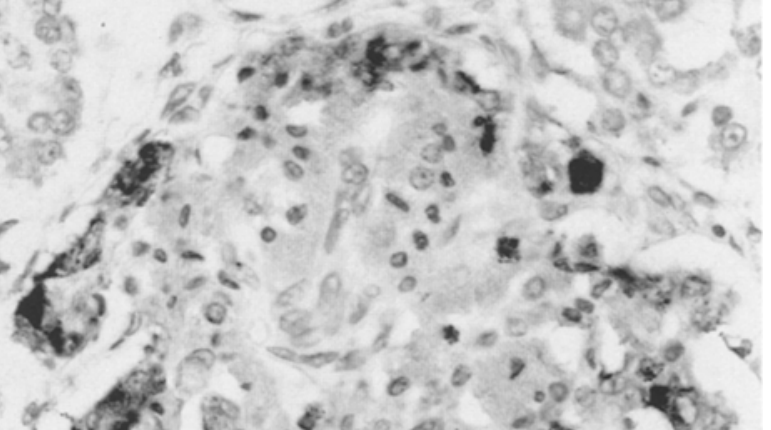
W.

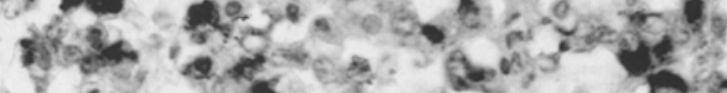

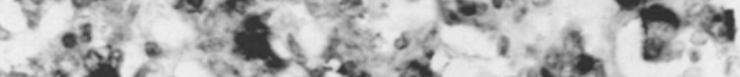

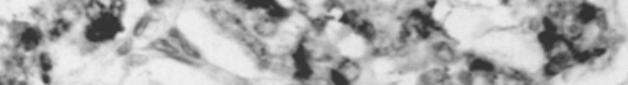

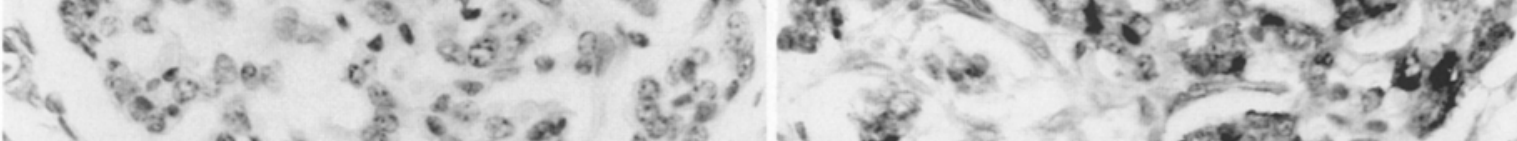

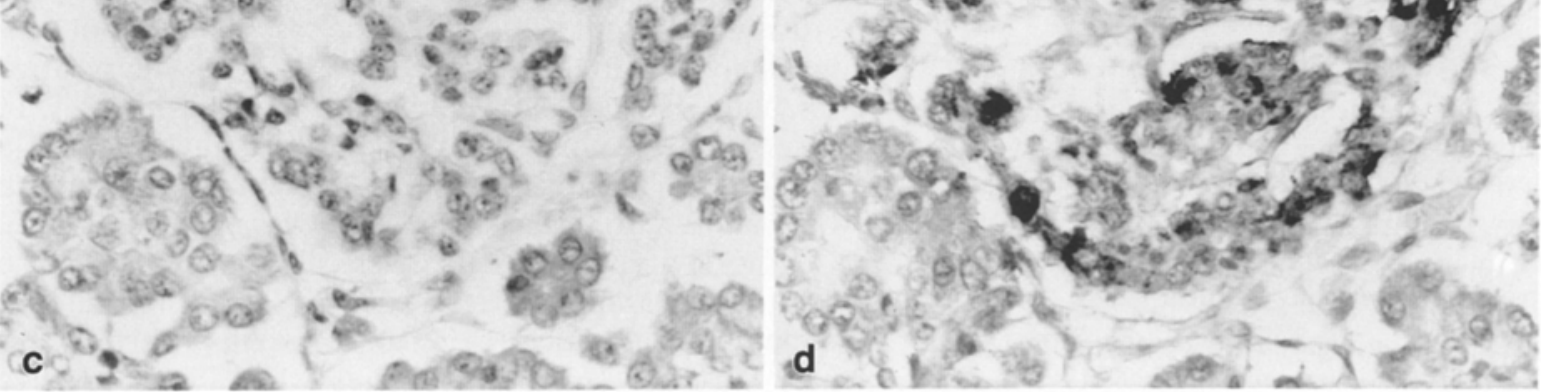



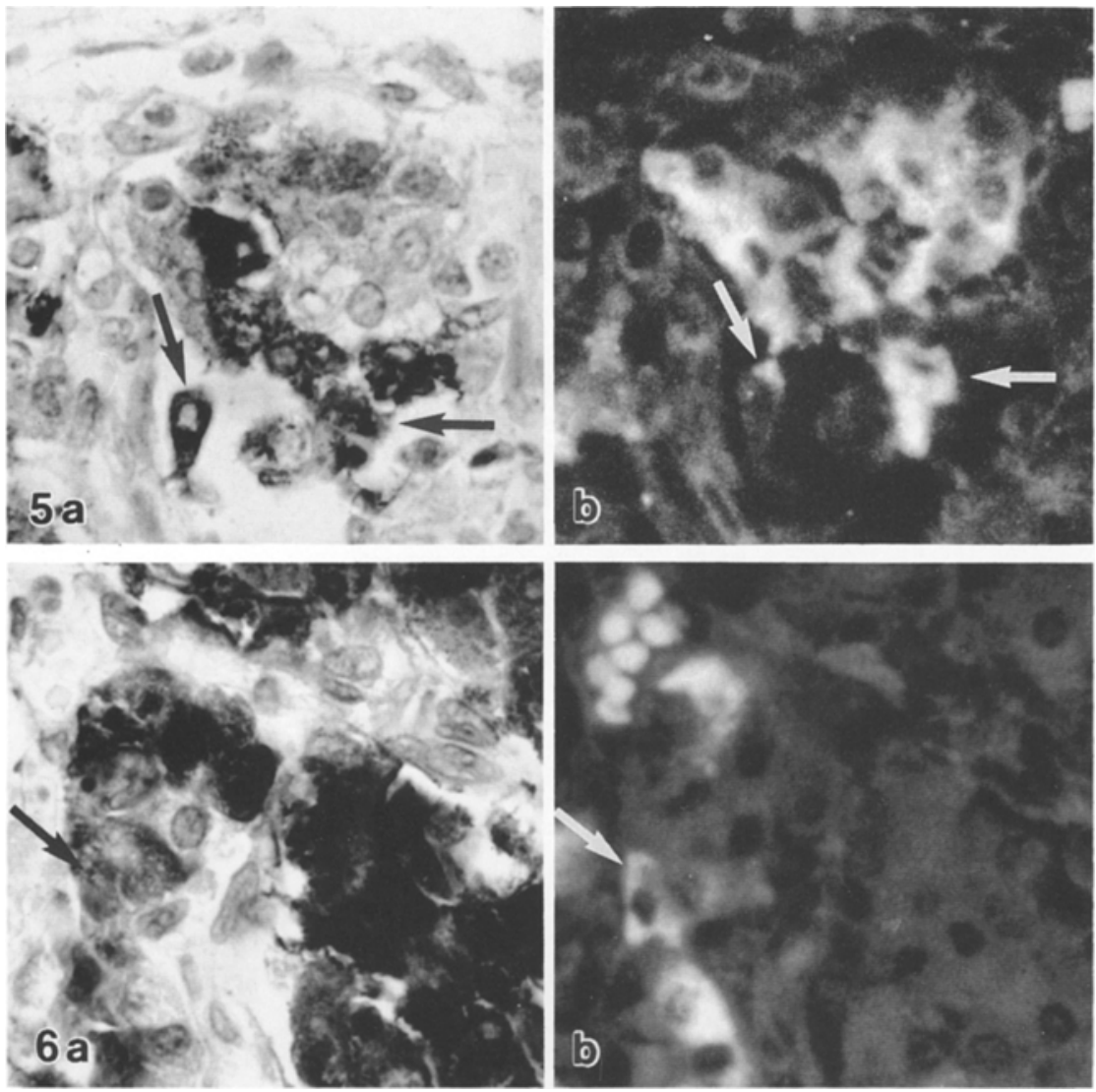

Fig.5 a and b. Coxsackie pancreatitis (case 3). This islet has been double immunostained for VP1 (a) and insulin (b). Several insulin containing cells express the VP1 protein (examples arrowed). $(\times 750)$

Fig. 6a and b. Coxsackie pancreatitis (Case 1). This islet has been double immunostained for VP1 (a) and glucagon (b). One glucagon containing Alpha cell shows positive black staining for VP1 in the cytoplasm above its nucleus (arrowed). $(\times 750)$ usually showed signs of early cell death with pyknotic nuclei.

Pancreas was available for study in 14 cases. In seven of the 12 infantile cases histological changes in the islets were seen. These were very extensive in cases 1 and 3 . In both these pancreases there was a marked inflammatory cell infiltrate which was present in the connective tissue between exocrine lobules and also centred around and within islets. The inflammatory cells included lymphocytes and macrophages and large numbers of eosinophils. In case 3 numerous eosinophils were also present in the myocardial inflammatory cell infiltrate. Affected islets showed evidence of islet cell necrosis with either pyknosis or loss of nuclei (Fig. 4a). On staining such islets for insulin and glucagon it could be seen that most pyknotic cells contained insulin (Fig. 4c). Definite examples of glucagon secreting A cells

Fig. 4a-d. Pancreas from child with coxsackie myocarditis (case 3). Serial sections have been stained by haematoxylin and eosin (a) and immunostained for VP1 (b), insulin (c) and glucagon (d). This islet is an example of a "polar" islet, found in fetal development and early neonatal life, where $B$ cells aggregate at one pole of the islet and A cells at the other. In a) endocrine cells with pyknotic (shrunken, dark) nuclei can be seen in the upper pole of the islet. In b) it can be seen that these dying cells express the VP 1 protein. Insulin containing $B$ cells are found in the upper islet pole c), and glucagon containing A cells are present primarily in the lower pole d). This shows that the coxsackievirus B3 in this case has tropism primarily for B cells. $(\times 410)$ showing signs of necrosis were also present. In none of the cases was there convincing evidence on haematoxylin and eosin staining of acinar or ductular cell necrosis and no inflammatory cell exudate was present within ducts.

Endocrine cells staining positively with antisera to both VP 1 and VP4/2/3 were present in all cases where insulitis was noticed histologically on the haematoxylin and eosin stained section. In one additional case (No.2) one small islet had endocrine cells positive for VP1 but not VP4/2/3. Necrotic cells were present within this islet on the section stained for VP1 but not VP 4/2/3. The islet was not present on the haematoxylin and eosin section. Sections from cases 1 and 3 were double-stained for VP 1 and insulin and also VP1 and glucagon. This confirmed that necrotic insulin containing cells were VP 1 positive and also that occasional glucagon cells (about one per islet section) appeared to be positive (Fig. 5, 6).

Cells positive for the capsid proteins were almost exclusively endocrine (Fig. 7). However, careful scanning of the sections of the heavily infected cases ( 1 and 3 ) showed occasional foci of positive acinar cells (Fig. 8). Ductular cells were consistently negative.

\section{Patients with Type 1 diabetes}

Pancreases from all 149 autopsies of diabetic patients were carefully screened for the presence of VP 1 . No positive staining was seen in islet endocrine cells or exocrine pancreatic cells. 


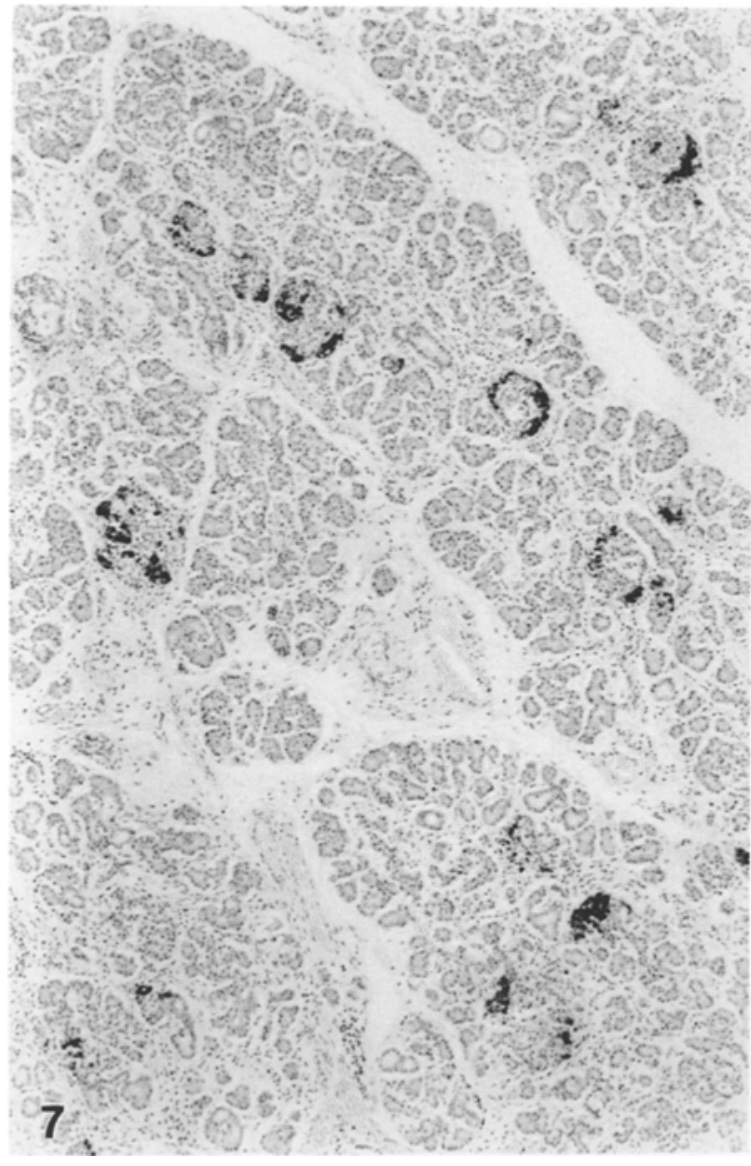

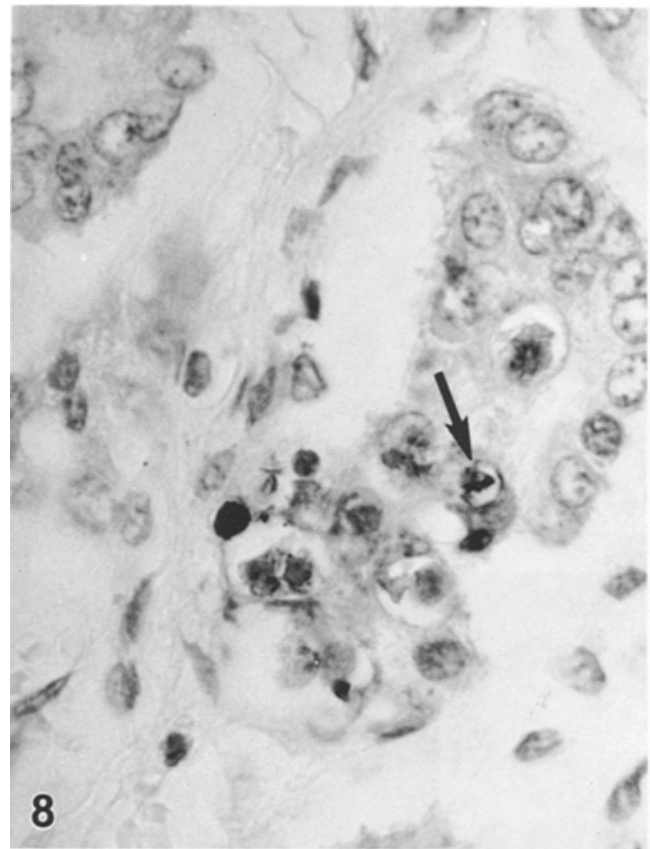

Fig. 7. Coxsackie pancreatitis (Case 1). This section has been immunostained for VP1. The viral protein is present exclusively in islets in this photograph. $(\times 50)$

Fig. 8. Coxsackie pancreatitis (Case 3). This section has been immunostained for VP1. Several pancreatic acinar cells, one of which is arrowed, express the protein in this picture. $(\times 700)$

\section{Control subjects' hearts and pancreases}

All normal hearts, inflammed and non-inflammed ischaemic hearts, normal pancreases and cases of non-viral pancreatitis showed no immunohistological evidence of the VP1 capsid protein.

\section{Discussion}

In the normal lytic cycle of a picornavirus, such as coxsackievirus, entry into the target cell is followed rapidly by an uncoating process leading to release of a single positive sense strand of RNA which acts as messenger RNA for the synthesis of all the viral proteins found in infected cells. The viral proteins are synthesized as one large polyprotein which is cleaved to produce the VP structural proteins and those proteins necessary for virus replication, such as RNA polymerase. RNA replication requires the production of a complementary negative sense strand which acts as a template for synthesis of more positive sense strands. The complete virion is assembled from single stranded, positive sense viral RNA strands encased in capsid proteins. Lysis of the infected cell occurs when a large number of such virions accumulate. The immunohistochemical techniques used in this study have been shown to be sensitive enough to detect capsid proteins in infected cells which are involved in a lytic cycle whether in vitro, in infected tissue culture cells, or in vivo, in the hearts and pancreases of infants with coxsackieviral myocarditis.

Conventional wisdom states that when coxsackie viruses infect a host they can be detected for the first 15 days of infection and thereafter are eliminated by the immune response. However, recent work has shown that these viruses can cause chronic infection. In some patients with postviral fatigue syndrome coxsackievirus can be isolated from the faeces over a period of a whole year [15]. Enteroviral RNA has been identified in myocardium of patients with cardiomyopathy up to 35 months after onset of symptoms [16-19] and in skeletal muscle in dermatomyositis or polymyositis after 18 months illness [20]. In these situations enteroviral RNA has been detected but the virus not cultured and it is not known in what molecular state the virus is present. In particular it is not known whether such incomplete viruses expresses VP1 capsid protein. It is against this background that the failure to find VP1 in diabetic pancreases should be viewed.

There are very few reports in the literature of attempts to demonstrate viruses in autopsy pancreas of patients who died at clinical presentation of Type 1 diabetes. In spite of this two reports have shown evidence of current infection. Yoon et al. cultured a coxsackievirus B 4 from the pancreas of their patient [5] and Gladisch et al. demonstrated a similar virus in islet endocrine cells by immunofluorescence [6]. It might be argued that even if VP1 were present in a diabetic pancreas it would not be de- 
monstrable by immunocytochemistry because the protein was already obscured by the patient's antibodies. This is unlikely because prior to cell lysis a cell containing VP1 protein would not be permeable to immunoglobulin and the capsid protein should therefore not be complexed to antibody. In practice, two of the infants where VP 1 was demonstrated in tissues were known to have raised titres to coxsackieviral antigens in life. Equally immunofluorescence was positive for coxsackieviral protein in both the case of Yoon et al. [5] and that of Gladisch [6] in the presence of raised antibody titres. The lack of detectable VP1 protein in diabetic pancreases in our cases therefore suggests that this disease is rarely the result of a massive synchronous destruction of B cells by enterovirus of the kind illustrated in Figure 7. Some authors have suggested that diabetes may be the result of a series of insults, each of which destroys a proportion of B cells. Our results suggest that even if this were the case the insult causing B cell destruction at the time of clinical diagnosis is rarely an enteroviral infection.

Our findings do not totally exclude the possibility that coxsackie viruses may have a role in the pathogenesis of some cases of Type 1 diabetes. We have confirmed the very marked tropism of these viruses to the endocrine pancreas in the infants with myocarditis. Such an infection, in patients with the appropriate genetic predisposition, may trigger an autoimmune response. When certain strains of mice are infected by coxsackievirus B3, myocarditis develops within 5-7 days of inoculation and persists for months thereafter. However, infectious virus can only be isolated from the heart up to 15 days after infection [21]. Two distinct cytotoxic T lymphocyte populations have been isolated from such animals - one specific for infected myocytes and one for uninfected myocytes. The presence of the latter population suggested the development of an autoimmune state [22]. Further evidence that such viruses can cause autoimmunity comes from the finding of enteroviral RNA in skeletal muscle in dermatomyositis and polymyositis [20] - diseases in which autoantibodies are found.

Destruction of B cells in most cases of Type 1 diabetes takes place over years [23, 24]. Evidence for a transient infection by a coxsackievirus which stimulated autoimmunity years before clinical presentation would be unlikely to be present in pancreases such as we have studied. However, two lines of evidence suggest that there could be a continuing infection of islet $\mathrm{B}$ cells. Firstly, the finding of IgM antibodies to coxsackieviruses in the serum of a proportion of Type 1 diabetic patients at clinical presentation is compatible with lack of viral clearance [4]. This is supported by the fact that in diseases such as dilated cardiomyopathy and postviral fatigue syndrome, where similar $\operatorname{IgM}$ antibodies have been described, evidence of continuing enteroviral infection has been found [15-19]. Secondly, insulin containing B cells in diabetes express alpha-interferon, which could be stimulated by the presence of a persistent virus [12].

Our findings are therefore not incompatible with the hypothesis that at clinical presentation in some cases of Type 1 diabetes there is a continuing infection of $\mathrm{B}$ cells by a defective non-cytopathic enterovirus which either does not express VP1 or which expresses very little of this protein. Such a virus is a possible candidate for an agent which could provoke the autoimmune destruction of $B$ cells which results in diabetes [25]. Attempts to demonstrate enteroviral RNA in diabetic pancreases by in situ hybridisation techniques [17-19] will now be made.

Acknowledgements. We are deeply indepted to Dr. M.R. Alderson of the Office of Population Censuses and Surveys, London, UK, and Prof. R. O.C. Kaschula of Cape Town, South Africa for helping to trace deaths from coxsackie virus in the UK, and Cape Town respectively. Dr. A. Gibson of the Department of Pathology, Royal Hospital for Sick Children, Glasgow provided much of the paediatric control material. We remain conscious of the tremendous generosity of all the pathologists who allowed their material to be examined. Mrs. I.O. Main and Miss E. Garrity kindly prepared the manuscript. M. McGill is supported financially by the British Diabetic Association.

\section{References}

1. Wolf E, Spencer KM, Cudworth AG (1983) The genetic susceptibility to Type 1 (insulin-dependent) diabetes: analysis of the HLA-DR association. Diabetologia 24: 224-230

2. Todd JA, Bell JI, McDevitt HO (1987) HLA-DQß gene contributes to susceptibility and resistence to insulin-dependent diabetes mellitus. Nature 329: 599-604

3. Tattershall RB, Pyke DA (1972) Diabetes in Identical Twins. Lancet II: $1120-1125$

4. Banatvala JE, Bryant J, Schernthaner G, Borkenstein M, Schober E, Brown D, De Silva LM, Menser MA, Silink M (1985) Coxsackie B, Mumps, Rubella, and Cytomegalovirus specific $\operatorname{IgM}$ responses in patients with juvenile-onset insulin-dependent diabetes mellitus in Britain, Austria and Australia. Lancet I: 1409-1412

5. Yoon JW, Austin M, Onodera T, Notkins AL (1979) Virus induced diabetes mellitus. N Engl J Med 300: 1173-1179

6. Gladisch R, Hofmann W, Waldherr R (1976) Myokarditis und Insulitis nach Coxsackie-Virus-Infekt. Z Kardiol 65: 837-849

7. Ujevich MM, Jaffe R (1980) Pancreatic Islet Cell Damage. Its occurence in neonatal Coxsackie virus encephalomyocarditis. Arch Path Lab Med 104: 438-441

8. Jenson AB, Rosenberg HS, Notkins AL (1980) Pancreatic isletcell damage in children with fatal viral infections. Lancet II: 354-358

9. Bottazzo GF, Dean BM, Mcnally JM, MacKay EH, Swift PGF, Gamble DR (1985) In situ characterization of autoimmune phenomena and expression of HLA molecules in the pancreas in diabetic insulitis. N Engl J Med 313: 353-360

10. Foulis AK, Farquharson MA (1986) Aberrant expression of HLA-DR antigens by insulin containing beta cells in recent onset Type 1 (insulin-dependent) diabetes mellitus. Diabetes 35: $1215-1224$

11. Foulis AK, Farquharson MA, Hardman R (1987) Aberrant expression of Class II major histocompatibility complex molecules by $\mathbf{B}$ cells and hyperexpression of Class I major histocompatibility complex molecules by insulin containing islets in Type I (insulin-dependent) diabetes mellitus. Diabetologia 30: 333-343

12. Foulis AK, Farquharson MA, Meager A (1987) Immunoreactive alpha-interferon in insulin-secreting beta cells in Type 1 diabetes mellitus. Lancet II: 1423-1427

13. Foulis AK, Jackson R, Farquharson MA (1988) The pancreas in idiopathic Addison's disease - a search for a prediabetic pancreas. Histopathology 12: 481-490

14. Werner S, Klump WM, Schönke H, Hofscheider PH, Kandolf R (1988) Expression of coxsackievirus B3 capsid proteins in 
Escherichia coli and generation of virus-specific antisera. DNA 7: 307-316

15. Yousef GE, Bell EJ, Mann GF, Murugesan V, Smith DG, McCartney RA, Mowbray JF (1988) Chronic enterovirus infection in patients with postviral fatigue syndrome. Lancet I: 146150

16. Bowles NE, Richardson PJ, Olsen EGJ, Archard LC (1986) Detection of Coxsackie-B-virus-specific RNA sequences in myocardial biopsy samples from patients with myocarditis and dilated cardiomyopathy. Lancet I: $1120-1122$

17. Kandolf R (1988) The impact of recombinant DNA technology on the study of enterovirus heart disease. In: Bendinelli M, Friedman H (eds) Coxsackieviruses - a general update. Plenum, New York, pp 293-318

18. Kandolf R, Ameis D, Kirschner P, Canu A, Hofschneider PH (1987) In situ detection of enteroviral genomes in myocardial cells by nucleic acid hybridization: an approach to the diagnosis of viral heart disease. Proc Natl Acad Sci USA 84: 6272-6276

19. Kandolf R, Hofschneider PH (1989) Viral heart disease. Springer Semin Immunopathol 11: 1-13

20. Bowles NE, Dubowitz V, Sewry CA, Archard LC (1987) Dermatomyositis, polymyositis and Coxsackie-B-virus infection. Lancet I: $1004-1007$

21. Rose NR, Herskowitz A, Neumann DA, Neu N (1988) Autoimmune myocarditis: a paradigm of post infection autoimmune disease. Immunol Today 9:117-120
22. Huber SA, Lodge PA (1984) Coxsackievirus B-3 myocarditis in $\mathrm{Balb} / \mathrm{c}$ mice. Evidence for autoimmunity to myocyte antigens. Am J Pathol 116: 21-29

23. Tarn AC, Smith CP, Spencer KM, Bottazzo GF, Gale EAM (1987) Type 1 (insulin dependent) diabetes: a disease of slow clinical onset? B Med J 294: 342-345

24. Mustonen A, Knip M, Huttunen N-P, Puukka R, Kaar M-L, Akerblom HK (1984) Evidence of delayed Beta cell destruction in Type 1 (insulin-dependent) diabetic patients with persisting complement-fixing cytoplasmic islet cell antibodies. Diabetologia 27: 421-426

25. Foulis AK (1989) Lawrence lecture. In Type 1 diabetes, does a non-cytopathic viral infection of insulin-secreting B-cells initiate the disease process leading to their autoimmune destruction? Diab Med 6: 666-674

Received: 24 July 1989

and in revised form: 27 November 1989

Dr. A. K.Foulis

Department of Pathology

Royal Infirmary

Glasgow, G4 OSF

UK 